\title{
Using Alkali-Activated Cementitious Materials to Solidify High Organic Matter Content Dredged Sludge as Roadbed Material
}

\author{
Zhong Gu, ${ }^{1}$ Sudong Hua ${ }^{D},{ }^{1}$ Weixing Zhao, ${ }^{2}$ Sisheng $L i,{ }^{3}$ Zhen Gao, ${ }^{3}$ and Haitao Shan ${ }^{3}$ \\ ${ }^{1}$ College of Materials Science and Engineering, Nanjing Tech University, Nanjing, Jiangsu 210009, China \\ ${ }^{2}$ Suqian Huayi Concrete Co., Ltd, Suqian, Jiangsu 223800, China \\ ${ }^{3}$ Suqian Highway Administration Office, Suqian, Jiangsu 223800, China \\ Correspondence should be addressed to Sudong Hua; huasudong@126.com
}

Received 6 May 2018; Revised 25 July 2018; Accepted 30 July 2018; Published 11 November 2018

Academic Editor: Robert Černý

Copyright (c) 2018 Zhong Gu et al. This is an open access article distributed under the Creative Commons Attribution License, which permits unrestricted use, distribution, and reproduction in any medium, provided the original work is properly cited.

It is difficult to treat dredged sludge with high organic matter content by solidification. A new solidification of dredged sludge with high organic matter content was developed, using cement, fly ash, slag, and phosphogypsum as a solidifier and strong oxidant $\mathrm{KMnO}_{4}$ and $\mathrm{GH}$ as additives, to improve the engineering performance of dredged sludge and make it as a roadbed material possible. The properties of the solidified samples were determined in terms of unconfined compressive strength, products of hydration, toxicity characteristics, water stability, freeze-thaw resistance, and volume stability. The microstructure and hydration products of the dredged sludge after solidification were evaluated by X-ray diffraction analysis, scanning electron microscopy, and thermogravimetry-differential scanning calorimetry analysis. Experimental results showed that the strength of the solidified samples has been significantly improved after treatment by strong oxidants. The effect of $\mathrm{GH}$ is better than that of $\mathrm{KMnO}_{4}$. Hydration products (ettringite) were well formed. After solidification by using the binders and strong oxidant GH, the samples had sufficient strength and good water stability performance, freeze-thaw resistance performance, and volume stability performance. The leach liquid of the dredged sludge solidified body meets the standard requirements. So, the dredged sludge after solidification can reach the requirement of the roadbed material.

\section{Introduction}

Increasing amount of dredged sludge has become an unavoidable environmental issue. High moisture content and rich organic matter are the most obvious characteristics of dredged sludge. In addition, dredged sludge contains pathogens, heavy metals, and other pollutants [1]. Conventionally, the dredged sludge is disposed via incineration, landfilling, or ocean disposal [2].

In general, dredged sludge are very soft soils $\left(C_{u}<50 \mathrm{kPa}\right)$ and the moisture content of dredged sludge is higher than its liquid limit [3]. Solidification is one of the best ways to deal with dredged sludge [4]. It can improve not only mechanical properties and engineering properties of dredged sludge but also its environmental properties [5]. Besides, solidification is a simple, convenient, and flexible technology which is suitable for handling large quantities of dredged sludge.
Dredged sludge can be used in many ways after solidification. It is a good method to use it for the public works [6]. Some scholars had used solidified dredged sludge as a road material [7-9]. Some scholars also used it as an embankment material [10]. Studies had reported that solidified river sediments can be made into highly insulating bricks [11].

Traditionally, cement [12], lime [13], slag [14], fly ash [15], etc., have been widely applied to solidification of dredged sludge. But due to the high water content and the high organic matter content in some dredged sludge, the solidification effect of dredged sludge may not be very good. It has been found that high organic matter content in dredged sludge obviously hinders the development of solidified sludge strength [16]. The organics can impede both the formation of cement hydration products and the interaction between sludge particles and the hydration 
products [17-19]. As a consequence, the compressive strength will decrease significantly.

Thus, some additives have been utilized during the cement-based solidification process in order to counteract the influences from the organic matters in dredged sludge. The feasibility of using bentonite as the additive had been studied due to its high adsorbability to organic substances [18]. It was reported that the CASC (mayenite/sulfoaluminate cement) hybrid binder showed an excellent efficiency on both water content reduction and strength development when solidified sludge with high organic content [19]. Another study showed that aluminate $12 \mathrm{Cao} \cdot 7 \mathrm{Al}_{2} \mathrm{O}_{3}$ as an accelerator could improve the performance of cement-based $S / S$, making the sludge disposal and recycling possible [20]. At present, the use of strong oxidants as additives to reduce the impact of organic matter on curing has not attracted special attention, as thus to date there have been no comprehensive studies in this aspect.

For the dredged sludge with high organic matter content, the major objective of this study was mainly to use cement and alkali-activated cementitious material (fly ash, slag, and phosphogypsum) to solidify dredged sludge as a roadbed material. Different strong oxidants $\left(\mathrm{KMnO}_{4}\right.$ and $\mathrm{GH}$ (configured by ourselves)) were chosen as additives to improve the solidification performance. There are two points to evaluate whether the dredged sludge can be used as a roadbed material after solidification: good mechanical properties and no harm to the environment. Therefore, the following tests were performed after the solidification: (1) unconfined compressive strength tests, (2) water stability tests, (3) freeze-thaw cycle tests, (4) expansion tests, and (5) leaching tests. The microstructure and hydration products of the dredged sludge after solidification were evaluated by $\mathrm{X}$-ray diffraction analysis, scanning electron microscopy, and thermogravimetry-differential scanning calorimetry analysis.

\section{Materials and Methods}

\subsection{Materials}

2.1.1. Dredged Sludge. The dredged sludge investigated in this study was from the river in the city of Shenzhen, China. The raw dredged sludge was taupe gray and possessed a somewhat unpleasant smell due to the presence of organic matter. The physical properties of the dredged sludge are shown in Table 1. The content of organic matter was determined by the method of burning loss. The dredged sludge was dried to a constant weight at $105-110^{\circ} \mathrm{C}$ for $4 \mathrm{~h}$ and then grounded finely for chemical composition analysis. The dried dredged sludge composition was analyzed by X-ray fluorescence (XRF). Test results are shown in Table 2, and the main components of dry dredged sludge were silica $\left(\mathrm{SiO}_{2}\right)$, ferric oxide $\left(\mathrm{Fe}_{2} \mathrm{O}_{3}\right)$, alumina $\left(\mathrm{Al}_{2} \mathrm{O}_{3}\right)$, etc.

2.1.2. Other Materials. In this experiment, cement and alkali-activated cementitious material (FA, slag, and PG) were selected as main curing materials. The cement is Conch 32.5 composite Portland cement manufactured by Anhui Conch Cement Co., Ltd. The chemical compositions of these
TABle 1: Physicochemical properties of dredged sludge used.

\begin{tabular}{lccccc}
\hline Parameters & \multicolumn{5}{c}{ Values } \\
\hline Moisture content (\%) & \multicolumn{4}{c}{124} \\
Organic matter content (wt.\%) & \multicolumn{2}{c}{$15.6 \%$} \\
$\mathrm{pH}$ & & & 7.4 & & \\
$\mathrm{Heavy}$ metals $(\mathrm{g} / \mathrm{kg})^{\mathrm{a}}$ & $\mathrm{Cu}$ & $\mathrm{Pb}$ & $\mathrm{Zn}$ & $\mathrm{Ni}$ & $\mathrm{Ba}$ \\
$\mathrm{Cr}$ & 0.223 & 0.008 & 0.089 & 0.061 & 0.102 \\
0.091 &
\end{tabular}

${ }^{\mathrm{a}}$ Concentration of heavy metals ( $\mathrm{g} / \mathrm{kg}$ dry dredged sludge).

materials are shown in Table 3. The chemical composition of the alkali-activated cementitious material (AACM) is shown in Table 4.

In addition, sodium hydroxide $(\mathrm{NaOH}, \mathrm{AR})$ and water glass were selected as alkali activators in this study. The concentration of sodium hydroxide is $96 \%$. The modulus of sodium silicate (water glass) is 2.24, and the solid content of water glass is 0.43 . Strong oxidant potassium permanganate $\left(\mathrm{KMnO}_{4}, \mathrm{AR}\right.$ ) and $\mathrm{GH}$ (configured by ourselves) were used to reduce the organic matter content, respectively. The concentration of $\mathrm{KMnO}_{4}$ is $99.5 \%$. The chemical composition of the strong oxidant GH is shown in Table 5.

\subsection{Experimental Methods}

2.2.1. Sample Preparation. The dredged sludge used in the experiment is taken out directly from the river, and its initial moisture content is higher than $200 \%$, which is difficult to solidify. Firstly, the dredged sludge was air-dried. Then, the stones and other debris were removed from the dredged sludge to ensure the uniformity of sludge. Water was added to the dried dredged sludge for controlling the moisture content at $70.8 \%$. Then, the strong oxidants $\mathrm{KMnO}_{4}$ and $\mathrm{GH}$ were added to the sludge, respectively. After 3 hours, dredged sludge was mixed with curing materials. The curing material comprised cement (PC 32.5) and alkali-activated cementitious material (FA, slag, and PG). The dosage of the curing material is $20 \%$ by weight of dredged sludge. The dosage of the activator is $10 \%$ by weight of the binder, configured in a $1: 9$ ratio of $\mathrm{NaOH}$ and water glass. After sufficient agitation, the material was pressed into $\Phi 50 \mathrm{~mm} \times$ $50 \mathrm{~mm}$ cylindrical specimens by molds and hydraulic jack. The specimens were cured for 7 and 28 days in a curing room with a relative humidity of $95 \%$ and a curing temperature of $(20 \pm 2)^{\circ} \mathrm{C}$, respectively.

\subsubsection{Road Property Evaluation}

(1) Unconfined Compressive Strength Tests. Unconfined compressive strength (UCS) is an important index which can reflect the rate of hydration reaction of solidified sludge [21]. A detailed experimental method could be found in the standard method JTG E51-2009. The instrument type of UCS tests is WHY-200 (Shanghai Hualong Test Instrument Co., Ltd). Mixing design for samples used in unconfined compressive strength tests is shown in Table 6. 
TABLE 2: Chemical compositions of dried dredged sludge.

\begin{tabular}{lcccccccccc}
\hline Composition & $\mathrm{Fe}_{2} \mathrm{O}_{3}$ & $\mathrm{SiO}_{2}$ & $\mathrm{Al}_{2} \mathrm{O}_{3}$ & $\mathrm{MgO}$ & $\mathrm{SO}_{3}$ & $\mathrm{TiO}_{2}$ & $\mathrm{R}_{2} \mathrm{O}$ & $\mathrm{P}_{2} \mathrm{O}_{5}$ & $\mathrm{CaO}$ & $\mathrm{LOI}$ \\
\hline Content (\%) & 7.26 & 43.52 & 21.24 & 1.49 & 1.67 & 0.813 & 2.727 & 1.25 & 1.11 & 17.83 \\
\hline
\end{tabular}

Note: $\mathrm{R}_{2} \mathrm{O}$ : alkali metal oxide; LOI: loss of ignition at $1000^{\circ} \mathrm{C}$.

TABLE 3: Chemical compositions of the solidification materials.

\begin{tabular}{lccccccccrr}
\hline Material & $\mathrm{SiO}_{2}$ & $\mathrm{Al}_{2} \mathrm{O}_{3}$ & $\mathrm{CaO}$ & $\mathrm{Fe}_{2} \mathrm{O}_{3}$ & $\mathrm{R}_{2} \mathrm{O}$ & $\mathrm{SO}_{3}$ & $\mathrm{MgO}$ & $\mathrm{TiO}_{2}$ & $\mathrm{P}_{2} \mathrm{O}_{5}$ & $\mathrm{LOI}$ \\
\hline PC 32.5 & 21.86 & 4.25 & 63.59 & 1.25 & 0.55 & 2.42 & 2.19 & 0.12 & - & 3.75 \\
FA & 46.45 & 38.40 & 3.45 & 3.78 & 1.03 & 0.64 & 0.63 & 1.50 & 0.6 & 2.87 \\
Slag & 32.54 & 16.36 & 38.16 & 0.30 & 0.64 & 1.15 & 7.35 & 0.59 & - & 0.93 \\
PG & 11.68 & 2.96 & 30.53 & 0.348 & 0.365 & 46.55 & 0.478 & - & 1.65 & 3.57 \\
\hline
\end{tabular}

Note: $\mathrm{R}_{2} \mathrm{O}$ : alkali metal oxide; LOI: loss of ignition at $1000^{\circ} \mathrm{C}$.

TABle 4: Chemical composition of AACM.

\begin{tabular}{lcccccccccc}
\hline Material & $\mathrm{SiO}_{2}$ & $\mathrm{Al}_{2} \mathrm{O}_{3}$ & $\mathrm{CaO}$ & $\mathrm{Fe}_{2} \mathrm{O}_{3}$ & $\mathrm{R}_{2} \mathrm{O}$ & $\mathrm{SO}_{3}$ & $\mathrm{MgO}$ & $\mathrm{TiO}_{2}$ & $\mathrm{P}_{2} \mathrm{O}_{5}$ & $\mathrm{LOI}$ \\
\hline AACM & 39.50 & 27.38 & 20.81 & 2.04 & 0.835 & 0.895 & 3.99 & 1.045 & 0.63 & 1.90 \\
\hline
\end{tabular}

Note: $\mathrm{R}_{2} \mathrm{O}$ : alkali metal oxide; LOI: loss of ignition at $1000^{\circ} \mathrm{C}$.

TABLE 5: Chemical composition of strong oxidant GH.

\begin{tabular}{lccccccccc}
\hline Composition & $\mathrm{Al}_{2} \mathrm{O}_{3}$ & $\mathrm{CaO}$ & $\mathrm{Fe}_{2} \mathrm{O}_{3}$ & $\mathrm{~K}_{2} \mathrm{O}$ & $\mathrm{SO}_{3}$ & $\mathrm{MgO}$ & $\mathrm{MnO}_{2}$ & LOI & Others \\
\hline Content (\%) & 3.24 & 3.50 & 6.41 & 48.20 & 25.45 & 2.02 & 2.24 & 6.80 & 2.14 \\
\hline
\end{tabular}

Note: LOI: loss of ignition at $1000^{\circ} \mathrm{C}$.

TABLE 6: Nomenclature and mixing design for samples.

\begin{tabular}{lccccccccc}
\hline Nomenclature & 1 & 2 & 3 & 4 & 5 & 6 & 7 & 8 \\
\hline Strong oxidant & $0 \% \mathrm{KMnO}_{4}$ & $2 \% \mathrm{KMnO}_{4}$ & $4 \% \mathrm{KMnO}_{4}$ & $6 \% \mathrm{KMnO}_{4}$ & $0 \% \mathrm{GH}$ & $2 \% \mathrm{GH}$ & $4 \% \mathrm{GH}$ & $6 \% \mathrm{GH}$ \\
\hline
\end{tabular}

Note: The dosage of the strong oxidant is the percentage of mass of the cementitious material.

(2) Water Stability Tests. The water stability of the solidified body is the ability of the solidified body to resist deformation after being saturated with water. The water stability of the solidified dredged sludge was evaluated by a water stability test. The test tested the water stability performance of the dredged sludge solidified body after immersion for 1 day, 3 days, and 5 days. The strength $\left(R_{0}\right)$ of the solidified samples cured for 28 days was tested. Then, the solidified samples were immersed in water and taken out after $n$ days, and the strength $\left(R_{n}\right)$ of the samples at that time was tested. The formula for calculating the water stability coefficient $(P)$ is as follows:

$$
P=\frac{R_{0}}{R_{n}}
$$

(3) Freeze-Thaw Cycle Tests. Freeze-thaw resistance refers to the ability of a cured body to resist deformation under freeze-thaw cycles. The test tested the freeze-thaw resistance of the dredged sludge solidified body after 5, 10, and 15 freeze-thaw cycles. Freeze-thaw cycle tests were performed by the standard method JTG_E51-2009. The strength of the solidified samples before the freeze-thaw cycle tests and the strength after $m$ cycles of the freeze-thaw tests were measured and recorded as $R_{0}$ and $R_{m}$, respectively. The formula for calculating the strength loss rate (BDR) is as follows:

$$
B D R=\frac{\left(R_{0}-R_{m}\right)}{R_{0}} \times 100 \%
$$

(4) Expansion Tests. Expansion tests were performed by the standard method GBT 50123-1999. The displacement meter reading at time $t$ is recorded as $Z_{t}$. The initial reading of the displacement meter at the beginning of the experiment is recorded as $Z_{0}$. The initial height of the samples was recorded as $h_{0}$. The formula for calculating the expansion rate $(\delta)$ is as follows:

$$
\delta=\frac{\left(Z_{t}-Z_{0}\right)}{h_{0}} .
$$

(5) Leaching Tests. Leaching tests were performed according to the horizontal vibration method (HJ 557-2010). The solutions are prepared at the liquid-to-solid ratio of $10 \mathrm{~L} / \mathrm{kg}$ and vibrated at $110 \pm 10 \mathrm{r} / \mathrm{min}$ for $8 \mathrm{~h}$ at $20^{\circ} \mathrm{C}$. After standing for $16 \mathrm{~h}$, these solutions were filtered through $0.45 \mu \mathrm{m}$ 
membrane, and the filtrates were subsequently analyzed for the heavy metals $(\mathrm{Cu}, \mathrm{Cr}, \mathrm{Zn}, \mathrm{Pb}, \mathrm{Ni}$, and $\mathrm{Ba})$ by using the Optima 2100 DV ICP-AES (PerkinElmer, USA).

2.2.3. Analytical Methods. The solidified samples were grounded into powder and screened through a 200-mesh screener and dried at $65^{\circ} \mathrm{C}$. The dried powder was used for X-ray diffraction analysis (XRD; Rigaku-2500, Japan) and thermogravimetry-differential scanning calorimetry analysis (TG-DSC; ATA409, NETZSCH, Germany). Scanning electron microscopy (SEM; JMS-5900, Japan) was used to analyze the morphology of the original and solidified sludge samples after curing for 28 days. Samples at every curing age were soaked in anhydrous ethanol to stop hydration and dried at $50^{\circ} \mathrm{C}$ for $12 \mathrm{~h}$. Then, the samples were mounted on $\mathrm{Al}$ stubs and gilt with $\mathrm{Au}$, with a working voltage of $15 \mathrm{kV}$.

\section{Results and Discussion}

3.1. Solidified Dredged Sludge Road Property Evaluation. Compressive strength, water stability, and freeze-thaw resistance are often detected performance indicators in the construction of roadbeds. Poor performance of both will affect the quality and life of roads. In addition, due to the expansion properties of phosphogypsum and phosphogypsum added to the formulation, the volume stability of the dredged sludge solidified soil as a roadbed filling material was evaluated.

3.1.1. Unconfined Compressive Strength. Figures 1 and 2 show the results of unconfined compressive strength at 7 days and 28 days, respectively, with different strong oxidant dosages. It can be observed that, with the increase of $\mathrm{KMnO}_{4}$ and $\mathrm{GH}$ dosages, the strength curves of the solidified samples show an increasing trend in 7 days and 28 days. By comparing Figures 1 and 2, the unconfined compressive strength of the solidified samples increased obviously with the increase of curing age.

In Figures 1 and 2, after pretreated by strong oxidants, the strength of the solidified samples had been significantly improved than that of the samples without adding strong oxidant for pretreatment. This observation indicated that the use of strong oxidant as a way to reduce the impact of organic matter on solidification is effective. This observation could be interpreted by the following principles: (1) organic matter has a strong adsorption effect on the sludge particles, which can inhibit the clay minerals in dredged sludge to react with hydration products $\mathrm{Ca}(\mathrm{OH})_{2}$. (2) The main reason to choose strong oxidant as additives is using its strong oxidizing property which can react with organic matter. By removing the side chain alkane, oxidation, and aging effect, the organic matter will decompose into small molecules, and the structure of organic matter will be changed. (3) The content of organic matter was decreased, and the inhibitory effect of organic matter on the hydration reaction was weakened [22]. The strength of the solidified samples was improved.

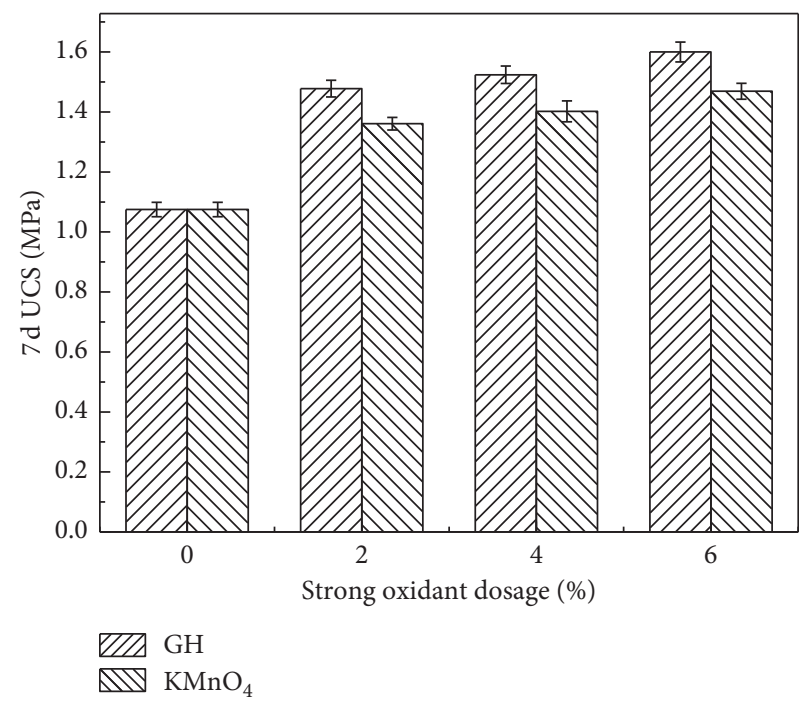

FIGURE 1: Unconfined compressive strength of samples added with different dosages of strong oxidant $(7 \mathrm{~d})$.

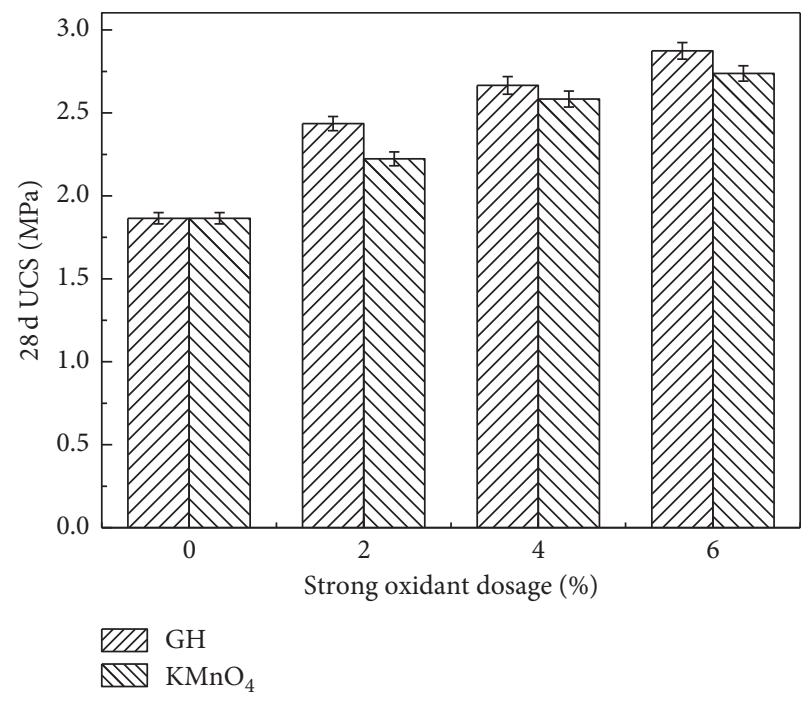

FIGURE 2: Unconfined compressive strength of samples added with different dosages of strong oxidant $(28 \mathrm{~d})$.

In addition, under the same dosage, the strength of the dredged sludge treated by GH is higher than that of the dredged sludge treated by $\mathrm{KMnO}_{4}$. For example, when the contents of $\mathrm{GH}$ and $\mathrm{KMnO}_{4}$ were $6 \%$, the unconfined compressive strength was $2.7 \mathrm{MPa}$ and $2.4 \mathrm{MPa}$ after curing for 28 days, respectively. Based on the above observations, it can be argued that the effect of $\mathrm{GH}$ is better than that of $\mathrm{KMnO}_{4}$. The reason may be that the dredged sludge used in the experiment was weakly alkaline which may cause partial $\mathrm{KMnO}_{4}$ decomposition. For taking into account cost-savings, the optimum dosage of strong oxidant is $2 \%$.

3.1.2. Water Stability. It can be seen from Figure 3 that the longer the time of immersion in the water, the lower the 

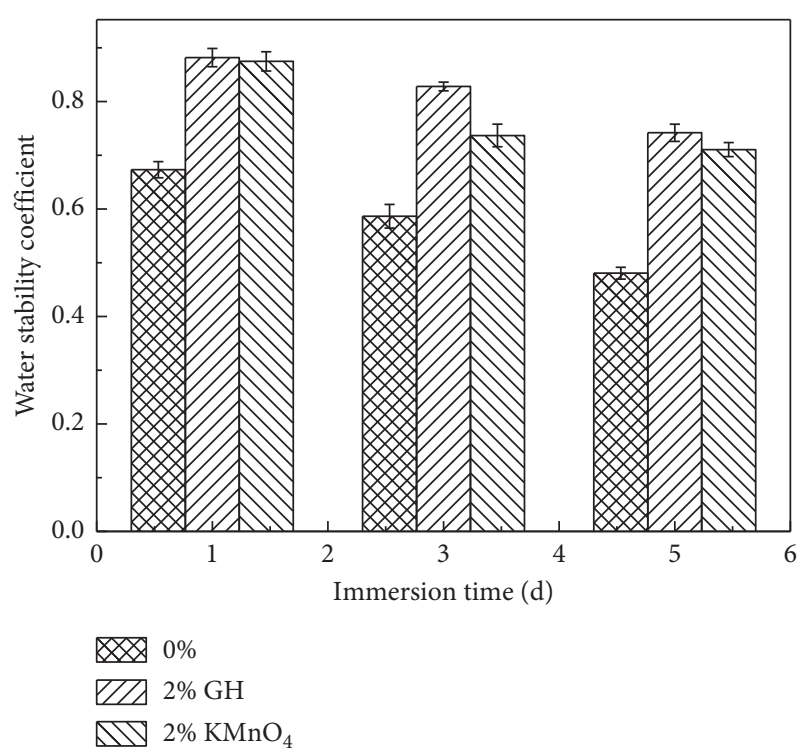

FIgURE 3: The water stability coefficient of the dredged sludge solidified body.

water stability coefficient of the dredged sludge solidified body. The solidified samples with $2 \% \mathrm{GH}$ had the best water stability. After immersing in water for 5 days, the water stability coefficient was about 0.75 . The water stability coefficient of the samples with $2 \% \mathrm{KMnO}_{4}$ after immersing in water for 5 days was 0.72 . The solidified samples without strong oxidant had the worst water stability. After immersing in water for 5 days, the water stability coefficient was only 0.48 .

The solidified samples with $0 \%$ strong oxidant had more pores, and the moisture easily penetrated into the solidified body. The solidified body structure even appeared to develop cracking, so the water stability was poor. Contrary to this, when $2 \% \mathrm{GH}$ was added, more hydrated products formed in solidified samples, and the solidified body had a more dense structure, which effectively blocked the infiltration of water. After solidification by using geopolymers and strong oxidant $\mathrm{GH}$, high organic matter content dredged sludge had good water stability.

3.1.3. Freeze-Thaw Resistance. As can be seen from Figure 4, the order of freeze-thaw stability of the dredged sludge solidified samples is as follows: the samples with $2 \% \mathrm{GH}>$ the samples with $2 \% \mathrm{KMnO}_{4}>$ the samples with $0 \%$ strong oxidant. The freeze-thaw cycle reduced the strength of the dredged sludge solidified body, and this reduction is more pronounced with the increase in the number of cycles. The strength loss rate was $9.8 \%$ after 15 freeze-thaw cycles in the solidified samples mixed with $2 \% \mathrm{GH}$, which still retained high strength.

This may be due to the fact that strong oxidant reduced the inhibition of the organic matter to the hydration reaction, and more hydrated products were produced inside the solidified samples, which made the structure of the solidified samples more compact and stable. Although the

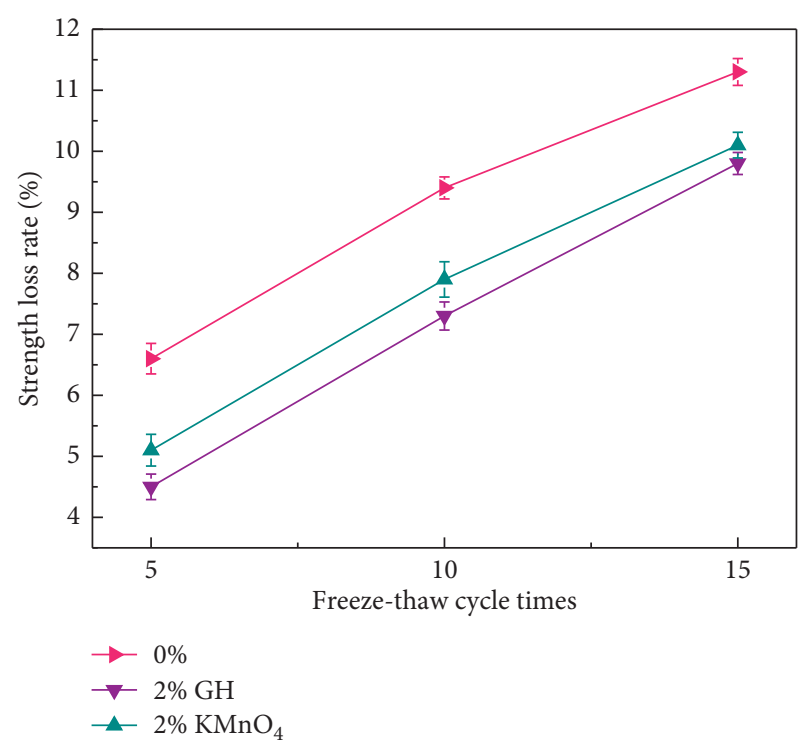

FIgURE 4: The strength loss rate of dredged sludge solidified body after freeze-thaw cycles.

freeze-thaw cycle destroyed some of the structures, the overall structure still had a high strength.

After solidification by using geopolymers and strong oxidant $\mathrm{GH}$, high organic matter content dredged sludge had good freeze-thaw resistance.

3.1.4. Volume Stability. The expansion rate of dredged sludge solidified soil at different test times can be seen from Figure 5. With the increase of time, the expansion rate of the 3 kinds of solidified samples showed an increasing trend, but after $20 \mathrm{~h}$, the expansion tended to be stable. At the same time, the dredged sludge samples solidified with $0 \%$ strong oxidant had the highest expansion rate, while the solidified samples with $2 \% \mathrm{GH}$ had the lowest expansion rate. When the time is $20 \mathrm{~h}$, the expansion rate of the solidified samples with $2 \% \mathrm{GH}$ was $0.41 \%$, while the expansion rate of the solidified samples with $0 \%$ strong oxidant was $0.48 \%$. It can be considered that, after solidification by using geopolymers and strong oxidant $\mathrm{GH}$, high organic matter content dredged sludge had good volume stability.

3.1.5. Leaching Tests. Leaching tests results of solidified dredged sludge samples are shown in Table 7 . The results showed that heavy metal concentrations in the extracts of solidified sludge were far below those of original sludge as well as regulatory limits in China (GB 5085.3-2007). This indicated that heavy metals were well immobilized in solidified dredged sludge by encapsulation or chemically immobilized in the cement hydrates $[23,24]$. As presented in Table 7, the stability of dredged sludge increased after the solidification process. The concentration of heavy metals in the samples pretreated with $2 \% \mathrm{GH}$ and $2 \% \mathrm{KMnO}_{4}$ was lower than that of the samples pretreated with $0 \%$ strong oxidant. This attributed to that strong oxidant improved the curing effect and the alkaline conditions of pore solution 


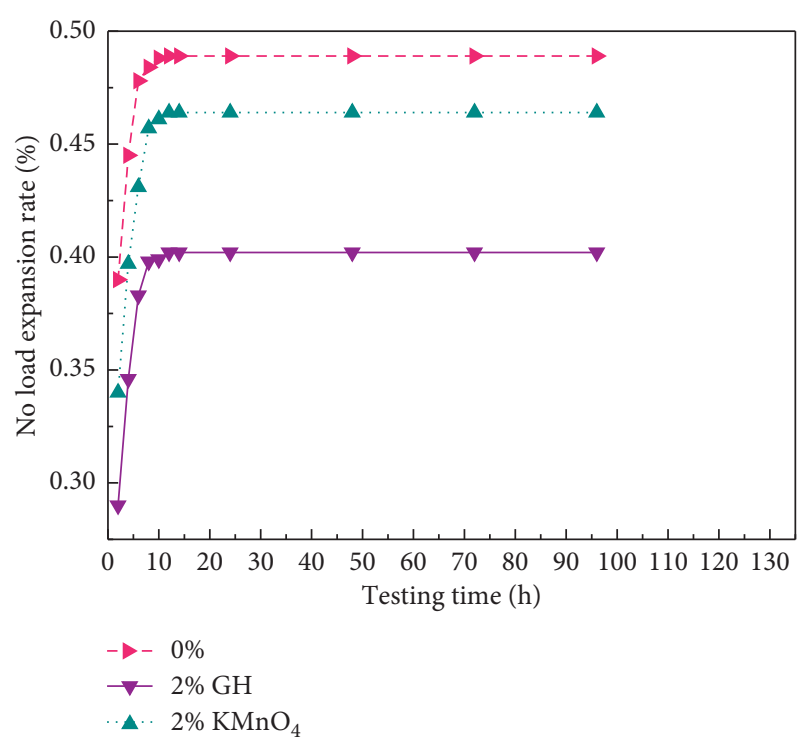

FIgURE 5: The expansion rate of dredged sludge solidified soil at different test times.

TABLE 7: Leaching tests results of solidified dredged sludge samples.

\begin{tabular}{lcccccc}
\hline Sample & $\begin{array}{c}\mathrm{Cr} \\
(\mathrm{mg} / \mathrm{L})\end{array}$ & $\begin{array}{c}\mathrm{Cu} \\
(\mathrm{mg} / \mathrm{L})\end{array}$ & $\begin{array}{c}\mathrm{Pb} \\
(\mathrm{mg} / \mathrm{L})\end{array}$ & $\begin{array}{c}\mathrm{Zn} \\
(\mathrm{mg} / \mathrm{L})\end{array}$ & $\begin{array}{c}\mathrm{Ni} \\
(\mathrm{mg} / \mathrm{L})\end{array}$ & $\begin{array}{c}\mathrm{Ba} \\
(\mathrm{mg} / \mathrm{L})\end{array}$ \\
\hline 0\% strong & nd & 0.135 & nd & 0.020 & nd & 2.72 \\
oxidant & & & & & & \\
$2 \% \mathrm{GH}$ & nd & 0.130 & nd & 0.017 & nd & 2.60 \\
$2 \% \mathrm{KMnO}_{4}$ & nd & 0.131 & nd & 0.015 & nd & 2.60 \\
Limits & 5 & 100 & 5 & 100 & 5 & 100 \\
\hline
\end{tabular}

Note: nd: not detected.

inside the solidified body help convert heavy metals from a dissolved phase to a solid phase and precipitate in the solidified body [25]. The increase of the strength of the solidified dredged sludge makes the heavy metal better encapsulated in the solidified body. It can be concluded that the dredged sludge after curing is harmless to the environment. This means that the use of dredged sludge solidified soil for road subgrade filling will not cause environmental pollution problems.

3.2. X-Ray Diffraction Analysis. Some representative samples that were cured for 28 days (raw dredged sludge, without strong oxidant, with $2 \% \mathrm{GH}$, and with $2 \% \mathrm{KMnO}_{4}$ ) which have a higher compressive strength were selected for $\mathrm{XRD}$ analysis (shown in Figure 6). It can be seen that the mineral composition of raw dredged sludge is mainly quartz, kaolinite, and muscovite.

With regard to solidified samples, the ettringite was produced which had the property of expansion. Ettringite can fill the gaps of solidification sludge and make the structure of solidification sludge compact. Besides the expansion action of ettringite, its crystal intertwined and reached a unique netted structure with hydration products which plays an important support role [26]. Some $\mathrm{CaCO}_{3}$ has also been identified. Thus, the unconfined compressive strength increased greatly with a large increase of the hydration products.

The peak intensity is an indication of a given hydrate content [27]. The type of binders resulted in considerable differences in the $\mathrm{XRD}$ spectra. Taking $\mathrm{CaCO}_{3}$ for example, the highest intensity of peak could be recorded in the mortar with $2 \% \mathrm{GH}$, followed by the sample with $2 \%$ $\mathrm{KMnO}_{4}$ and the sample without strong oxidant. This verified that adding strong oxidant could offset the interference of organic substances, favor the hydration reaction, induce the formation of a large quantity of hydrates, and subsequently increase the strength of solidified sludge [28].

When cement, geopolymer, and activators were added to the dredged sludge, the binders first reacted with the moisture in the dredged sludge to produce various hydration products [29]. Some of these hydration products continue to harden themselves and form the cement stone skeleton, while others further react with clay minerals such as silicates and aluminates in the dredged sludge.

Moreover, through the ion exchange and agglomeration, the hydration product makes the smaller dredged sludge particles form larger soil agglomerates, and the adsorption activity of the gel can make the larger soil agglomerates further cemented to form the agglomerate structure.

The high content of $\mathrm{CaO}$ in geopolymers can produce hydrated calcium silicate and can react with aluminate to produce large amounts of ettringite which can fill part of the pores. Besides, the ettringite forms a spatial structure together with the hydrated calcium silicate and further improves the strength of solidified samples.

Besides, free $\mathrm{Ca}(\mathrm{OH})_{2}$ can absorb $\mathrm{CO}_{2}$ in water and air, and carbonization reaction occurs to generate waterinsoluble $\mathrm{CaCO}_{3}$. This reaction can also increase the strength of solidified samples.

3.3. Thermal Analysis. TG-DSC was done for the samples (with $0 \%$ strong oxidant, with $2 \% \mathrm{GH}$, and with $2 \% \mathrm{KMnO}_{4}$ ) aged for 28 days to validate the results obtained from XRD analysis. The data analysis results are depicted in Figure 7. As in the XRD results, the thermal analysis reflected the differences in phase composition of hydrated pastes [21].

At about $100^{\circ} \mathrm{C}$, the weight loss occurred and exhibited a weak peak in the TG curves, which might be attributed to the evaporation of free and bound water of dredged sludge $[20,28]$. When the temperature was up to $250-350^{\circ} \mathrm{C}$, a little endothermic peak appeared. The reaction about removal of water from hydrated products happened which is likely to include among others most of C-S-H $[20,28]$. A weak peak appeared at around $450^{\circ} \mathrm{C}$, which was mainly due to the dehydroxylation of few $\mathrm{Ca}(\mathrm{OH})_{2}[18,28]$. A weak peak appearing at around $750^{\circ} \mathrm{C}$ is due to the decarbonation of $\mathrm{CaCO}_{3}$. Among them, the $\mathrm{CaCO}_{3}$ endothermic peak of the sample with $2 \% \mathrm{GH}$ is most obvious, followed by the sample with $2 \% \mathrm{KMnO}_{4}$ and the sample with $0 \%$ strong oxidant. Furthermore, a little endothermic peak at $950^{\circ} \mathrm{C}$, without change of weight, is attributed to 


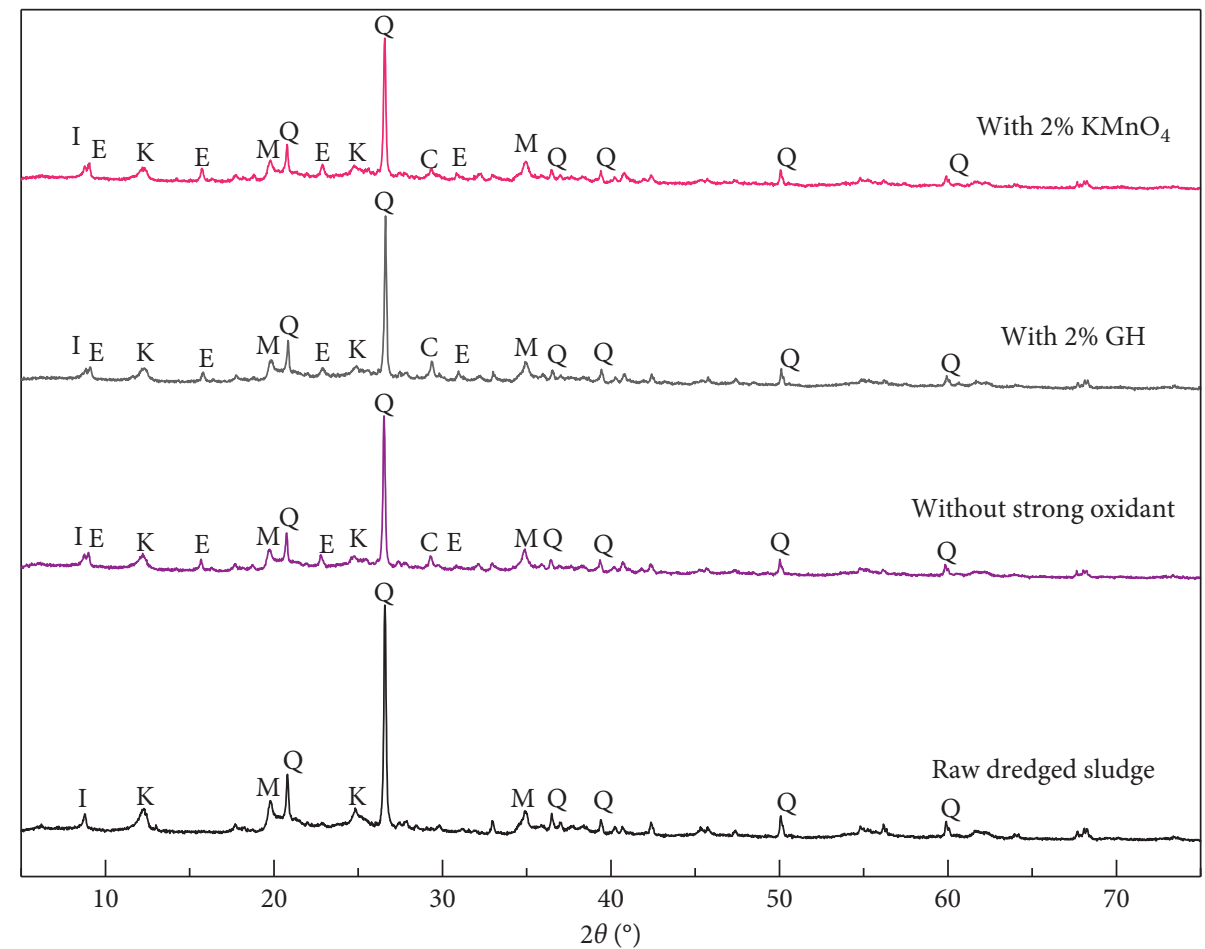

FIGURE 6: XRD patterns of raw dredged sludge and solidified samples. Q: quartz; K: kaolinite; E: ettringite; I: illite; $\mathrm{M}_{\text {: }}$ muscovite; $\mathrm{C}$ : $\mathrm{CaCo}_{3}$.

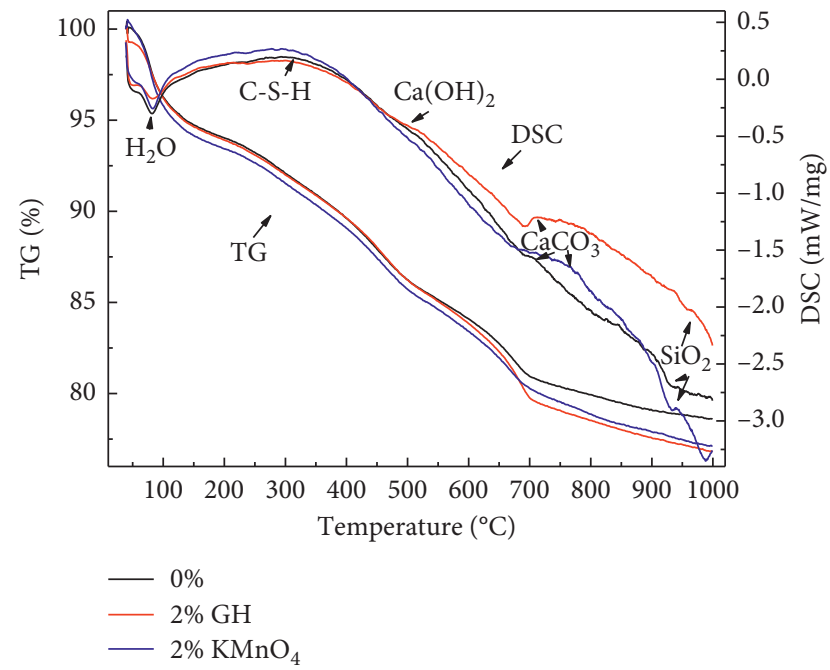

Figure 7: TG-DSC curves of the different samples after curing for 28 days.

$\mathrm{SiO}_{2}$ conversion, from anhydrous crystalline state to $\beta-\mathrm{SiO}_{2}$ and cristobalite $[18,28]$.

3.4. Scanning Electron Microscopy Analysis. Scanning electron microscopy results of dried dredged sludge and solidified sludge (after curing for 28 days) are shown in Figures 8 and 9. It can be noted from Figures 8(a) and 9(a) that the dredged sludge structure is loose before curing, and the soil particles are simply stacked. The gap between the particles is larger. There is no connection among soil particles; therefore, the strength of sludge is low. However, in comparison to Figures $8(\mathrm{~b})-8(\mathrm{~d})$, the structure of the solidified body became more compact after solidification for 28 days and the pores of the dredged sludge were reduced. This attributed to a large amount of hydration products which were filled between the dredged sludge particles $[30,31]$. The gel products were cemented together, so the specimens were hardened efficiently.

Besides, by comparing Figures 8 (b)-8(d), it can be seen that there is no obvious difference in the compactness of samples. However, as seen in Figures 9(c) and 9(d), many needle-like crystals formed on the surface of the sludge particles. These crystals may be the hydration products of minerals in the solidified materials and the reaction products between geopolymer and the sludge: ettringite which confirmed the results of XRD analysis [18]. The sludge particles were agglomerated together and formed a dense network structure through the hydration products. The structure of the solidified body was made more compact. The hydration products played an important role in improving the structural strength and stability of solidified sludge. A large amount of hydration product makes the structure of the solidified body denser. So, a higher UCS value was obtained for the solidified samples which were pretreated by strong oxidant.

\section{Conclusion}

(1) After using alkali-activated cementitious material and strong oxidant, better solidification effect can be obtained. Compared with the samples without treated with strong oxidant, the strength of the 

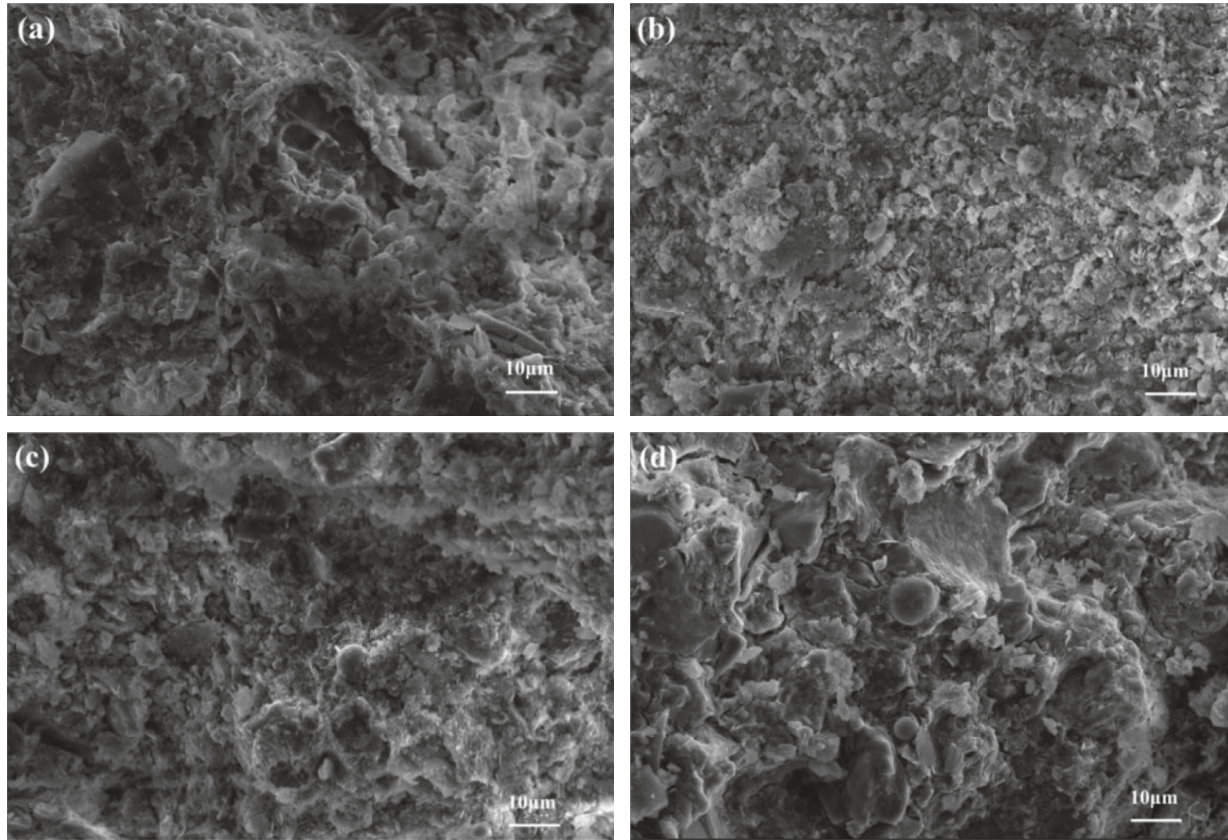

FIGURE 8: SEM images of dried dredged sludge and solidified sludge after curing for 28 days: (a) dried dredged sludge; (b) with $0 \%$ strong oxidant; (c) with $2 \% \mathrm{GH}$; (d) with $2 \% \mathrm{KMnO}_{4}$.
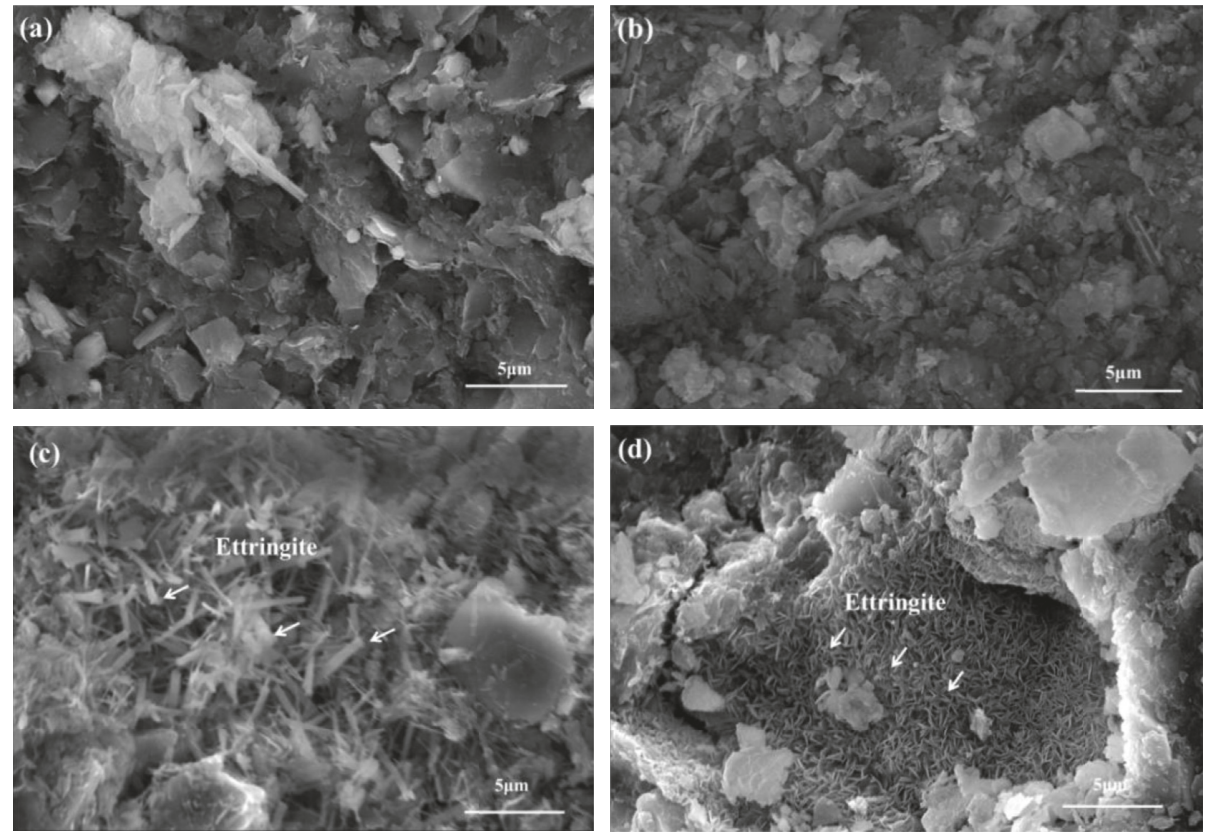

FIGURE 9: SEM images of dried dredged sludge and solidified sludge after curing for 28 days: (a) dried dredged sludge; (b) with $0 \%$ strong oxidant; (c) with $2 \% \mathrm{GH}$; (d) with $2 \% \mathrm{KMnO}_{4}$.

solidified samples with $\mathrm{KMnO}_{4}$ and $\mathrm{GH}$ has been significantly improved. Besides, the effect of $\mathrm{GH}$ is better than that of $\mathrm{KMnO}_{4}$. Taking into account cost-savings, the optimum dosage of strong oxidant is $2 \%$.

(2) XRD and SEM analysis clearly showed that hydration products (ettringite) were well formed. Thermal analysis verified the above results. The solidification process can improve the structural integrity of the dredged sludge and produce sufficient strength for the dredged sludge.

(3) After solidification by using the binder and strong oxidant $\mathrm{GH}$, high organic matter content dredged sludge had sufficient strength and good water stability performance, freeze-thaw resistance performance, and volume stability performance. The leachate of the dredged sludge solidified body meets the standard requirements. So, after solidification by 
using the binder and strong oxidant $\mathrm{GH}$, the dredged sludge can be used as a roadbed material.

\section{Data Availability}

The data used to support the findings of this study are available from the corresponding author upon request.

\section{Conflicts of Interest}

The authors declare that there are no conflicts of interest regarding the publication of this paper.

\section{Acknowledgments}

This project was supported by the Jiangsu Higher Education Institutions for a Project PAPD (Priority Academic Program Development), the Highway Science Research Program in Jiangsu Province (grant number E3213010313201709126), and the Jiangsu Province Science, Technology Support Plan Project (grant number BE2017704).

\section{References}

[1] D. Baruzzo, D. Minichelli, S. Bruckner et al., "Possible production of ceramic tiles from marine dredging spoils alone and mixed with other waste materials," Journal of Hazardous Materials, vol. 134, no. 1-3, pp. 202-210, 2006.

[2] V. K. Tyagi and S. L. Lo, "Sludge: a waste or renewable source for energy and resources recovery?," Renewable and Sustainable Energy Reviews, vol. 25, pp. 708-728, 2013.

[3] W. Zhu, C. L. Zhang, and C. F. Chiu Abraham, "Soil-water transfer mechanism for solidified dredged materials," Journal of Geotechnical and Geoenvironmental Engineering, vol. 133, no. 5, pp. 588-598, 2007.

[4] S. Paria and P. K. Yuet, "Solidification-stabilization of organic and inorganic contaminants using portland cement: a literature review," Environmental Reviews, vol. 14, no. 4, pp. 217255, 2006.

[5] P. Thanalechumi, A. R. M. Yusoff, M. Ponraj et al., "Studies on potential of Portland cement mortar for binding of waterworks sludge to reduce heavy metal leaching," Sādhan $\bar{a}$, vol. 41, no. 3, pp. 359-367, 2016.

[6] R. Zentar, N.-E. Abriak, and V. Dubois, "Beneficial use of dredged sediments in public works," Environmental Technology, vol. 30, no. 8, pp. 841-847, 2009.

[7] D. X. Wang, N. E. Abriak, R. Zentar et al., "Solidification/ stabilization of dredged marine sediments for road construction," Environmental Technology, vol. 33, no. 1, pp. 95101, 2012.

[8] V. Dubois, N. E. Abriak, R. Zentar et al., "The use of marine sediments as a pavement base material," Waste Management, vol. 29, no. 2, pp. 774-782, 2009.

[9] M. Miraoui, R. Zentar, and N. E. Abriak, "Road material basis in dredged sediment and basic oxygen furnace steel slag," Construction and Building Materials, vol. 30, pp. 309-319, 2012.

[10] J. Park, Y. H. Son, S. Noh, and T. Bong, "The suitability evaluation of dredged soil from reservoirs as embankment material," Journal of Environmental Management, vol. 183, pp. 443-452, 2016.

[11] Y. Xu, C. H. Yan, B. T. Xu, X. Ruan, and Z. Wei, “The use of urban river sediments as a primary raw material in the production of highly insulating brick," Ceramics International, vol. 40, no. 6, pp. 8833-8840, 2014.

[12] W. Na, "Utilization of portland cement and municipal solid waste incineration fly ash for solidification/stabilization of sewage sludge," Nature Environment and Pollution Technology, vol. 14, no. 1, pp. 141-144, 2015.

[13] Z. Wang, S. F. Xu, and G. C. Wang, "Study of early strength and shrinkage properties of cement or lime solidified soil," Energy Procedia, vol. 16, pp. 302-306, 2012.

[14] H. Cho, J. H. Shim, and J. Y. Park, "Performance evaluation of solidification/stabilization of dredged sediment using alkaliactivated slag," Desalination and Water Treatment, vol. 57, no. 22, pp. 10159-10168, 2016.

[15] R. Zentar, D.-X. Wang, N. E. Abriak, M. Benzerzour, and W. Chen, "Utilization of siliceous-aluminous fly ash and cement for solidification of marine sediments," Construction and Building Materials, vol. 35, pp. 856-863, 2012.

[16] O. Malliou, M. Katsioti, A. Georgiadis, and A. Katsiri, "Properties of stabilized/solidified admixtures of cement and sewage sludge," Cement and Concrete Composites, vol. 29, no. 1, pp. 55-61, 2007.

[17] H. Chen and Q. Wang, "The behaviour of organic matter in the process of soft soil stabilization using cement," Bulletin of Engineering Geology and the Environment, vol. 65, no. 4, pp. 445-448, 2006.

[18] M. Katsioti, N. Katsiotis, G. Rouni et al., "The effect of bentonite/cement mortar for the stabilization/solidification of sewage sludge containing heavy metals," Cement and Concrete Composites, vol. 30, no. 10, pp. 1013-1019, 2008.

[19] D. Xin, X. Chai, and W. Zhao, "Hybrid cement-assisted dewatering, solidification and stabilization of sewage sludge with high organic content," Journal of Material Cycles and Waste Management, vol. 18, no. 2, pp. 356-365, 2016.

[20] G. Y. Zhen, X. Q. Lu, X. B. Cheng et al., "Hydration process of the aluminate $12 \mathrm{CaO} \cdot 7 \mathrm{Al} 2 \mathrm{O} 3$-assisted Portland cementbased solidification/stabilization of sewage sludge," Construction and Building Materials, vol. 30, pp. 675-681, 2012.

[21] L. Li, W. Zhu, Y. Qu et al., "Mechanism of clay mineral effect on strength of solidification sludge," Journal of Environmental Science and Engineering, vol. 4, no. 7, pp. 30-35, 2010.

[22] W. Zhu, C. F. Chiu, C. L. Zhang et al., "Effect of humic acid on the behaviour of solidified dredged material," Canadian Geotechnical Journal, vol. 46, no. 9, pp. 1093-1100, 2009.

[23] S. Bouzalakos, A. W. L. Dudeney, and C. R. Cheeseman, "Controlled low-strength materials containing waste precipitates from mineral processing," Minerals Engineering, vol. 21, no. 4, pp. 252-263, 2008.

[24] X. G. Li, L. Yang, B. G. Ma et al., "Utilization of municipal solid waste incineration bottom ash in blended cement," Journal of Cleaner Production, vol. 32, pp. 96-100, 2012.

[25] H. Y. Zhang, B. Wang, X. L. Dong et al., "Utilization of municipal solid waste incineration bottom ash in blended cement," Science in China Series E: Technological Sciences, vol. 52, no. 7, pp. 1906-1912, 2009.

[26] G. Salihoglu, V. Pinarli, N. K. Salihoglu et al., "Properties of steel foundry electric arc furnace dust solidified/stabilized with Portland cement," Journal of Environmental Management, vol. 85, no. 1, pp. 190-197, 2007.

[27] C. Lin, W. Zhu, and J. Han, "Strength and leachability of solidified sewage sludge with different additives," Journal of Materials in Civil Engineering, vol. 25, no. 11, pp. 1594-1601, 2013.

[28] G. Y. Zhen, X. F. Yan, H. Y. Zhou, H. Chen, T. Zhao, and Y. Zhao, "Effects of calcined aluminum salts on the advanced 
dewatering and solidification/stabilization of sewage sludge," Journal of Environmental Sciences, vol. 23, no. 7, pp. 12251233, 2011.

[29] D. G. Wareham and J. R. Mackechnie, "Solidification of New Zealand harbor sediments using cementitious materials," Journal of Materials in Civil Engineering, vol. 18, no. 2, pp. 311-315, 2006.

[30] Y. C. Chen, L. X. Wang, P. Song, and Q. Wang, "Effects of magnesium potassium phosphate cements mixed with silica fume on the solidification and reduction of municipal sludge," Materials Science and Engineering, vol. 167, no. 1, pp. 1-7, 2017.

[31] S. L. Li, L. L. Wei, Q. L. Zhao et al., "Solidification efficiency and mechanism of conventional curing agents for sewage sludge stabilization and dewatering," Journal of Harbin Institute of Technology, vol. 22, no. 6, pp. 1-10, 2015. 


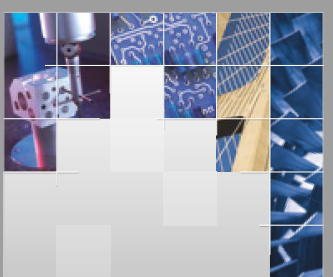

\section{Enfincering}
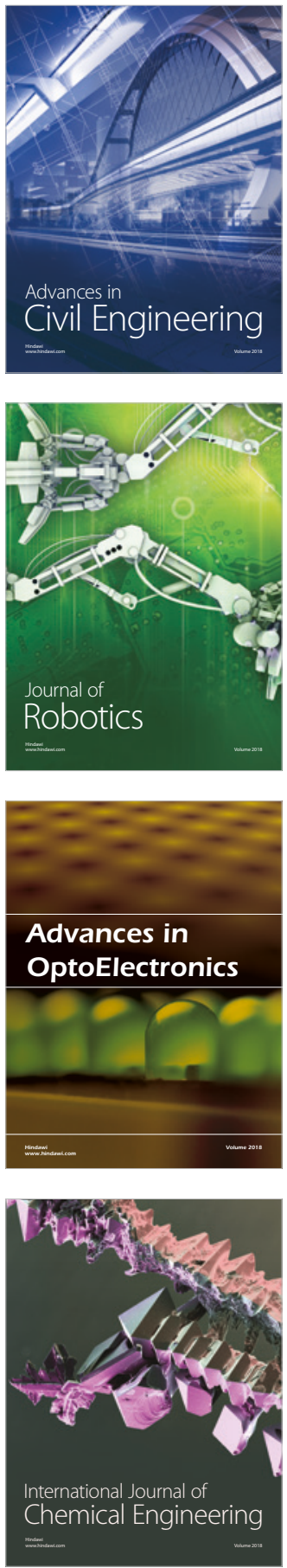

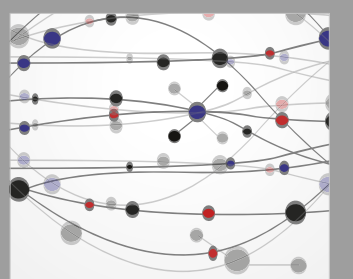

\section{Rotating \\ Machinery}

The Scientific World Journal

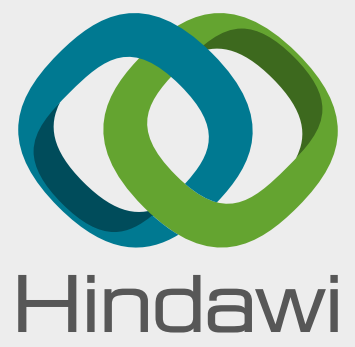

Submit your manuscripts at

www.hindawi.com
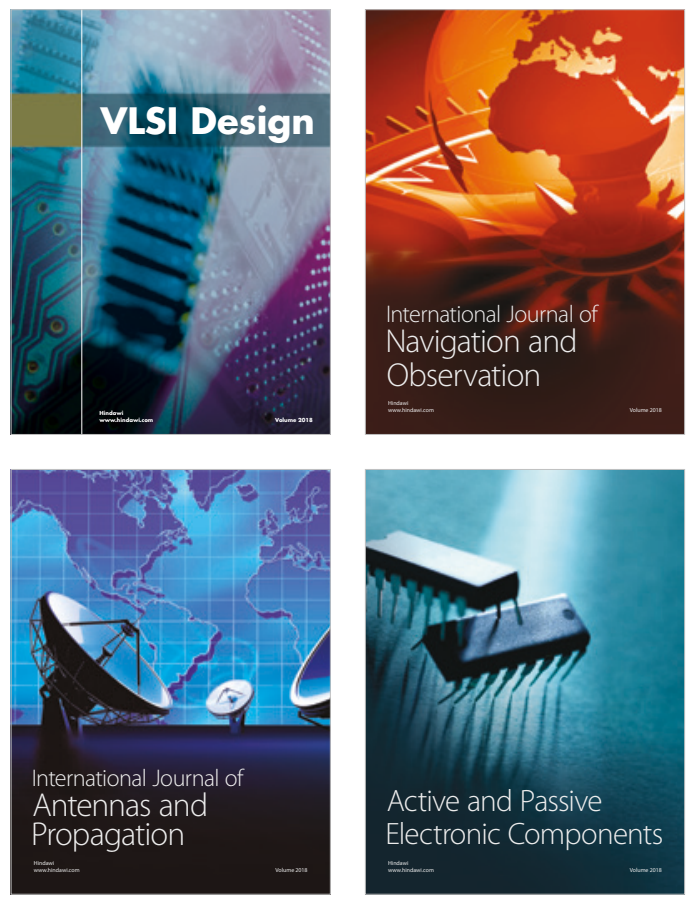
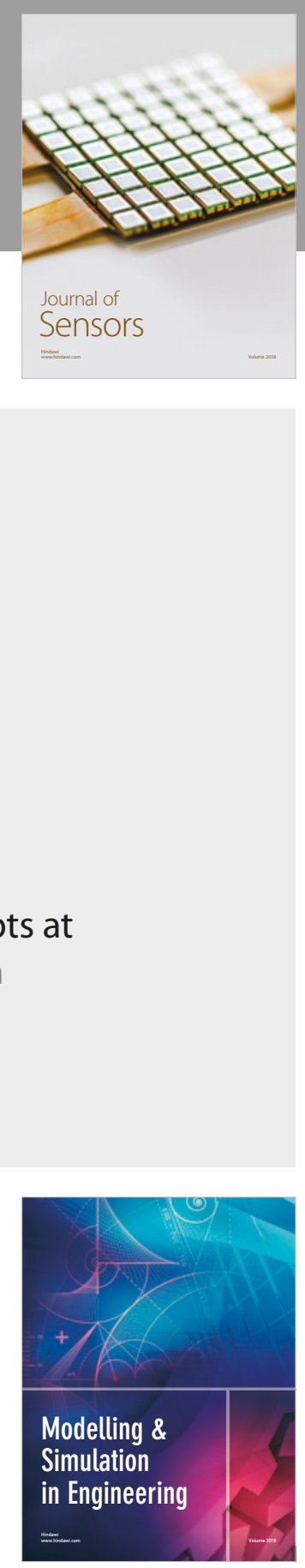

\section{Advances \\ Multimedia}
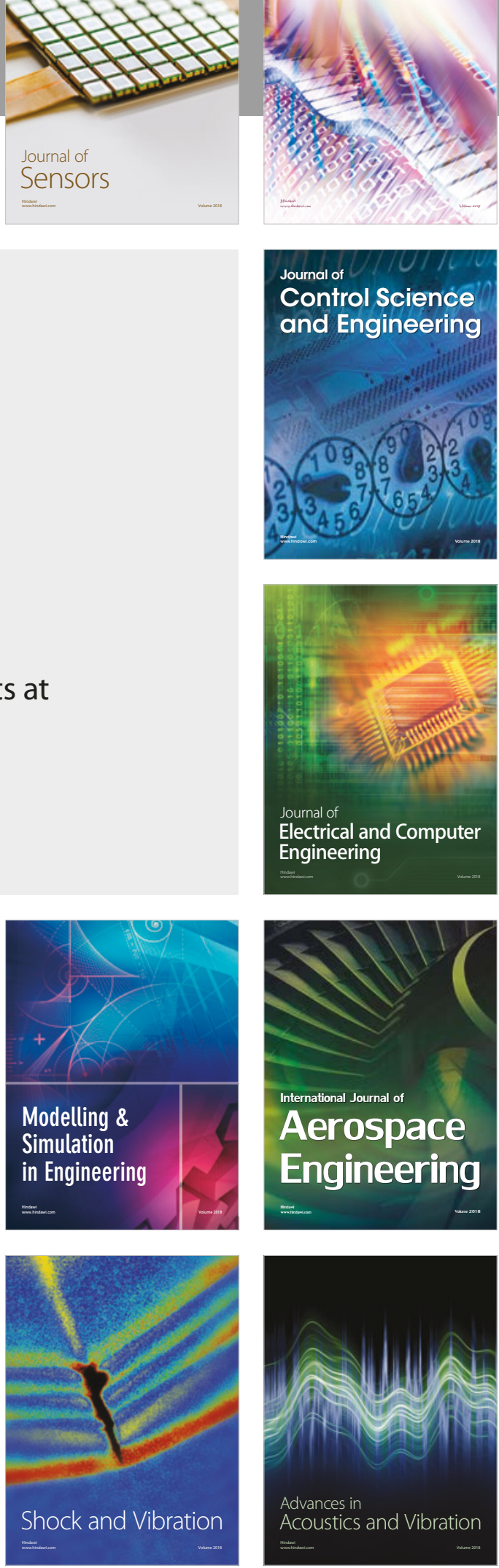